www.emakalat.com

ISSN 1309-5803

Mezhep Araştırmaları Dergisi 12 , sy. 1 (Bahar 2019): 197-204

Journal of Islamic Sects Research 12, no. 1 (Spring 2019): 197-204

Kitap Tanıtımı | Book-Review

\title{
SECTARIANISM IN THE MIDDLE EAST: IMPLICATIONS FOR THE UNITED STATES
}

Heather M. Robinson, Ben Connable, David E. Thaler, Ali G.

Scotten, RAND Corporation, 2019, 144 s.

Habib KARTALOĞLU*

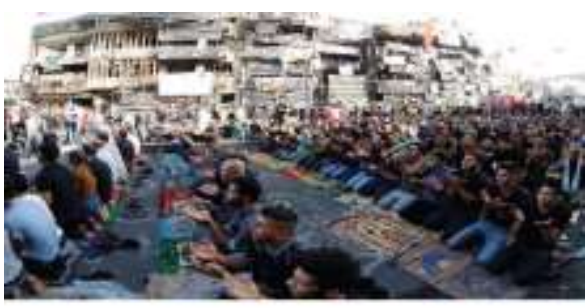

19. yüzyılın ortalarından itibaren Bat1 merkezli bir kavramsallaştırma olan Ortadoğu, dünya tarihinin merkez bölgesi ve bulunduğu coğrafya itibariyle doğu ve batı arasinda jeo-stratejik bir kavşaktır. Tarihin akışını değiştiren olayların yaşandığı

\section{Sectarianism in the} Middle East

Implications for the United States

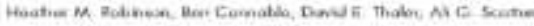

Ortadoğu, aynı zamanda kadîm medeniyetlerin kurulduğu, üç büyük semavî dinin doğduğu, farklı dinî grupların, etnik/sosyal yapıların bir arada yaşadığ kültür havzasıdır. Bu temel özelliklerin yanı sira sanayileşmeyle birlikte ihtiyaç duyulan zengin fosil enerji kaynaklarının büyük bir kısmının

bölgede bulunuyor olmasiyla bölge, dünya siyasetine yön vermek isteyen devletlerin ekonomi-politik güç sahasina dönüşmüştür. Dolayısıyla son yüz yılda bölge, siyasi istikrarsızlığın yanı sıra etnik, dinî/mezhebî çatışmaların ve toplumsal hareketlerin yaşandığı bir coğrafya haline gelmiştir.

* Dr. Öğr. Üyesi, Sakarya Üniversitesi İlahiyat Fakültesi, İslam Mezhepleri Tarihi Anabilim Dalı, hkartaloglu@sakarya.edu.tr.

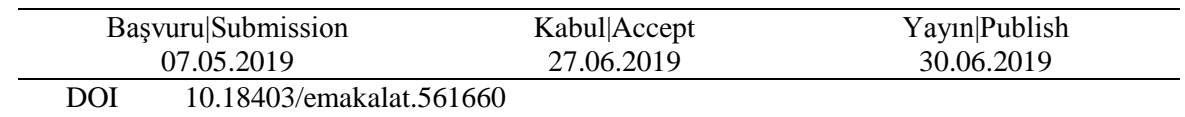


Dünya siyasetine yön vermeyi iddia eden devletlerde olduğu gibi Amerika Birleşik Devletleri de küresel güç haline gelmeye başladığı yirminci yüzyılın başlarından itibaren Ortadoğu coğrafyasıyla yakından ilgilenmektedir. İkinci Dünya Savaşı sonrasında bölgedeki etkisini giderek artıran ABD, özellikle Soğuk savaş sonrası dönemde bölgenin en önemli küresel aktörü haline gelmiştir. Körfez savaşılla bölgeye bilfiil müdahale eden $\mathrm{ABD}$, kendi dış politikasını belirlemek için bölgenin mevcut durumunu analiz eden sayısız çalışmalar yaptırmıştır. Yapılan bu çalışmalardan bir kısmı bizzat devletin birimleri tarafından desteklenirken diğerleri de çeşitli düşünce kuruluşlarının katkılarıyla yapılan çalışmalardır. ${ }^{1}$ Hiç kuşkusuz politika belirleyicilere malzeme sunan bu çalışmalar/raporlar, coğrafyanın sadece siyasi ve ekonomik boyutuyla ilgili olmayıp aynı zamanda bölgedeki etnik unsurlar, sosyo-kültürel yapılar, dinler/inançlar ve mezhebi oluşumlar hakkındadır.

Ortadoğu ile ilgili mevcut durumun bu şekilde tespitinin yapılması bölge hakkında hazırlanan çalışmaların/raporların önemini daha belirgin hale getirmektedir. $\mathrm{Bu}$ itibarla değerlendirmesini yapacağımız "Sectarianism in the Middle East: Implications for the United States" başl1kl1 rapor, "Implications of a Religious War in the Middle East for the U.S. Army" başl1kl 1 bir projenin parçası olarak yürütülen araştırma ve incelemeyi konu edinmektedir. United States Army ${ }^{2}$ tarafindan desteklenen bu projenin asıl amacı, son zamanlarda iç çatışmanın en çok yaşandığ Irak ve Suriye ekseninde Ortadoğu'da mezhepçiliği ele almak ve politika yapıcılara veriler sunmaktır (s. iii).

Beş ana bölümden oluşan bu raporun birinci bölümünde araştırmacılar, dinî toplumsal kimliğin siyasallaşması (s. 2) olarak tanımladıkları mezhepçilik ve Ortadoğu'da mezhep çatışmasına yol açan temel faktörlerin analizinde niçin özellikle Irak ve Suriye

1 Örneğin 2018 yılında The Washington Institute tarafindan desteklenen bir çalışma için bk. Fabrice Balanche, Sectarianism in Syria's Civil War (Washington: Washington Institute for Near East Policy, 2018).

2 Department of the Army, Deputy Chief of Staff, G-8, Army Quadrennial Defense Review Office tarafindan desteklenen bu proje, RAND Arroyo Center'ın strateji, doktrin ve kaynaklar programı kapsamında yapılmıştır. RAND Corporation'in bir parçası olan RAND Arroyo Center ise United States Army tarafindan desteklenen bir araştırma merkezidir. 
seçildiği üzerinde durmaktadır. Buna göre bu iki ülkenin seçilmesinin asıl sebebi, günümüzde bölgede mezhep ekseninde çatışmaların en fazla bu iki ülkede yaşanıyor olmasıdır. Bu bölümde araştırmada yararlanılan kaynakların niteliğine de değinen araştırmacılara göre, bir kimsenin mezhepsel aidiyeti, ulusal, etnik, sınıfsal ve diğer aidiyetleri de içeren kimliğinin sadece bir parçasıdır. Politik ve sosyal çevre bireyin kimliğinin hangi yönünün ön plana çıkacağını büyük ölçüde etkiler (s. 2). Öte yandan Ortadoğu'da mezhep temelli şikâyetlerin artmasından yönetim baskıları etkili olmuştur. Zira baskıcı yönetimler kişilerin siyasi görüşlerini ifade etmelerine izin vermediklerinden birçok insan etnik köken veya din gibi dışa tanımlanabilir kimlikleri öne çıkararak örgütlenmeye zorlanmaktadır. Yönetimlerin baskısı ve istikrarsızlığı Ortadoğu'da mezhepçi kimliğin önemini artırmaktadır. Ancak büyük çaplı mezhepsel şiddet, yerli ve yabanc1 aktörlerin kendi siyasi amaçları için toplumsal çatışmaya yol açma konusundaki kasıtlı çabalarının bir sonucudur (s. 3).

Çalışmanın "The History of Sectarianism in the Middle East" başlıklı ikinci bölümünde günümüzde mezhepçiliğin geldiği durumu anlamak için 1300 yıllık Sünnî - Şî̂ mezhepsel çatışmanın tarihi özetle ele alınmaktadır. Zira mezhebî kimliklerin bölge insanına olan etkisini belirtmek için tarih boyunca Sünnîler ve Şiîler arasındaki mezhepçiliğin doğasını ortaya koyabilmek önemlidir (s. 9). Bu bağlamda ilk olarak, bölgedeki mezhepçiliğin tabiatının tarihsel olarak şekillenmesinde rol oynamıs demografik yapı hakkında bilgiler verilmektedir. Günümüzde Müslüman nüfusun yaklaş1k \% 85 'ini Sünnîler ve\% 15 'ini de Şiîlerin oluşturduğu ifade edilen raporda (s. 11), Ortadoğu haritası (SSekil 2.1) üzerinden bölgede bulunan Şîi ve Sünnî nüfusuna dâir oranlar verilmektedir. Ancak bu kısımda verilen oranların bir kısmında ciddi hatalar bulunmaktadır. Örneğin Türkiye için verilen oran \%25-30'dur. Bu orana Şî̂lerin altında yer aldığ1 iddia edilen Alevîler de dâhil edilmektedir. Oysa Alevîler, kendilerini on iki imam Şiîliğiyle hiçbir şekilde ilişkilendirmemektedirler. Ayrıca Alevîliğin kültürel kaynaklarında, Şiîlikle ilgili bazı kavramlara yer verilmiş olmasına rağmen Şiîliğin inanç esaslarına atıflar yapılmamakta ve fikıh ve amele dâir söz konusu mezhepte bulunan uygulamalara rastlanmamaktadır. Diğer taraftan 
raporda ülkelere göre Şiî nüfus oranının, Şîa altında ortaya çıkmış firkalara göre verilmesi kanaatimizce daha isabetli olacaktır.Nitekim raporda Suriye nüfusunun \%15’inin Şiî olduğu belirtilmektedir. Ancak bugün Suriye'de yaşayan Şiîlerin çoğunluğunu Nusayrîler oluşturmaktadır. Bu bağlamda Fabrice Balanche'in 2018 yılında Suriye üzerinde hazırlamış olduğu rapordan da istifade edilerek bu kısım daha açık hale getirilebilirdi. Zira Balanche, çalışmasında Suriye'de bulunan \% 15'lik Şiî nüfusu, daha net ve doğruya yakın bir şekilde (Alevîler (Nusayrîler) \%10, Şiîler \%1, İsmâilîler \%1 ve Dürzîler \%3) verilmektedir. ${ }^{3}$

Bölgede yaşayan Sünnî ve Şiîlere ait nüfus oranlarının verilmesinin ardından raporda, Ortadoğu'da mezhepçiliğin tarihi, "Early History and the Sunni-Shi'a Divide", "Middle Ages: 800-1500", "Early Modern Era: 1500-1920", "Modern Era: 1900-1979" ve "Contemporary Era: 1979-Present" şeklinde alt başliklar halinde ele alınmaktadır. Ortadoğu'da mezhepçiliğin tarihinin niçin bu şekilde bir dönemlendirme ile ele alındığı hakkında bir açıklamaya yer verilmemiş olmasına rağmen raporun kendi içerisinde bir bütünlüğünün olduğu anlaşılmaktadır. Zira İmâmiyye mezhebini kabul eden Safevî Devleti'nin 1501 yılında Tebriz merkezli olarak ortaya çıktığı veya 1979 yılında İran İslam Cumhuriyeti'nin kurulduğu göz önüne getirildiğinde bu daha iyi anlaşılacaktır. $\mathrm{Bu}$ bölümlerde araştırmacılar, incelenen her bir dönemde vuku bulan mezhep çatışmasının öncelikli olarak din üzerinden olup olmadığını, ardından bölünmelerin itikâdî farklılıklar mı yoksa politik, ekonomik veya başka nedenlerden mi olduğu üzerinde durmaktadırlar. Mezhepçiliğin modern bir olgu olmadığının altı çizilen raporda, tarihi süreçte Sünnîler ve Şiîler arasında vuku bulan ayrışmanın/uyuşmazlığın kökeninde itikadî meseleler kadar olmasa da siyâsî, coğrafi, ekonomik, etnik ve diğer konuların da eşit bir rol oynadığı iddia edilmektedir.

“Modern Era: 1900-1979" alt başlığında Osmanlı Devleti'nin y1kılışının Orta Doğu siyasetinde bir dönüm noktası olduğu ve Batılı devletlerin Osmanlı topraklarını "modern" ulus devletlere benzeyen parçalara böldükleri vurgulanmaktadır (s. 18). Ayrıca Fransız ve

3 Balanche, Sectarianism in Syria's Civil War, 22. 
İngilizlerin her bir ülkeyi idare etmek için bir mezhep lehine bir strateji izlemelerinin yanı sıra sömürülen devletleri zayıf kılmak ve yöneticilerini güvende tutmak için mevcut mezhepsel bölünmeleri teşvik ettikleri ve bunun da modern Ortadoğu'da mezhepçiliğin daha derin köklere kavuşmasına zemin hazırladığı iddia edilmektedir (s. 18-19).

$\mathrm{Bu}$ bölümün son alt başlığında ise 1979 sonrası dönem ele alınmaktadır. Rapora göre İran İslam Devrimi, günümüz Ortadoğu'sundaki mezhepçiliğinin başlangıç noktasıdır. Zira İran ve Suudi Arabistan arasindaki artan bölgesel rekabet, son yıllarda bölgede yükselen mezhepçiliği anlamanın anahtarı mesabesindedir. Öte yandan İran'in bölgedeki gücünün artmasında ABD'nin Afganistan'daki (2001) ve Irak'taki (2003) müdahaleleri ve her iki ülkede İran yanlısı hükümetlerin kurulmasının etkisi bulunmaktadır (s. 22). Bir önceki alt başl1kta İngiliz ve Fransızların bölgede mezhepçiliğin kökleşmesine sebep oldukları ifade edilmiş olmasına rağmen Soğuk savaş sonrası dönemde bölgeye bilfiil müdahale eden ABD'nin bu konudaki lehte/aleyhteki rolüne hiç değinilmemektedir.

Çalışmada örneklem olarak seçilen Irak'ta mezhepçiliğin ele alındığ1 üçüncü bölümde konu, "Pre-Ba'ath Sectarianism: Challenging Assumptions and Tracing Identities", "Ba'ath-Era Sectarianism and Other "-isms", "Post-Ba'ath Sectarianism" ve "Implications of Sectarian Division for the Iraqi State and the Region" alt başlıkları altında ele alınmaktadır. Son zamanlarda Irak üzerinde araştırma yapan birçok kişi, Iraklıların etnik ve mezhepsel iç savaşa doğru sürüklendiklerini, Irak milliyetçiliğinin asıl gerçeği maskeleyen bir durum olduğunu ve Irak devletinin kaçınılmaz bir şekilde etnomezhepsel devrime yöneldiğini varsaymaktadır. Raporun bu kısminda Irak'taki mevcut Sünnî- Şî̂ bölünmesinin nasıl ortaya çıktığı, geliştiği ve çeşitli işgalci güçlerin öngörüsüzlükleriyle beslendiği şeklindeki genel varsayımların bir kısmı doğrulanmaktadır. Bununla birlikte rapora göre, hem Sünnî hem de Şiî Iraklılar kendilerine hizmet eden fakat karşıt mezhepçi ve hatta milliyetçi ilişkiler kurma kapasitesine sahiptirler (s. 23). Ayrıca Arap Iraklı kimlikler, tamamen mezhep kaynaklı olmaktan daha fazla karmaşıktır. Bu varsayım çerçevesinde raporun bu bölümünün ilk 
kısmında özelikle Osmanlı döneminden 1960'larda Baas devrimine kadar geçen sürece odaklanarak Irak'taki uzun ve karmaşı mezhepsel bölünme tarihi özetlenmektedir. Müslüman Iraklıların yaklaş1k \%75-80'inin Arap olduğu Irak'ta, Müslüman nüfusun yarıdan fazlası Şiî'dir (s. 27). Raporun bu kısmında 18. yüzyılın sonlarından itibaren başlayıp 20. yüzyılın başarından itibaren artan bir oranda Irak'ta Sünniler ve Şiîler arasında mezhepçi milliyetçi kimliğin güçlendiği ve bu dönemde her iki mezhebin yapısını şekillendiren değişimlerin olduğu vurgulanmaktadır. Bu çerçevede de özellikle 1920-1968 yılları arası esas alınarak Sünnî ve Şî̂ kimlik ayrı ayrı ele alınmaktadır (s. 33-39). Rapora göre Baas öncesi Irak kimliğinin incelenmesinde genel çerçevenin önemli bir kısmını bu iki mezhepsel kimlik oluşturmaktadır. Bununla birlikte Irak kimliğinin daha detaylı irdelenmesinde bu iki ana unsurun yanı sıra kabilecilik (tribalism) ve bununla yakından ilgili olan bölgeselcilik (regionalism) gibi faktörlerin de etkisinin olduğu görülmektedir (s. 39-41).

Baas dönemi (1968-2003) ve sonrasının ele alındığ alt başlıklarda konu Sünnîler ve Şiîler ekseninde ele alınmakta ve özellikle Baas döneminde (1968-2003) mezhepçiliğin artması ve güçlenmesinde Arap Sosyalist Baasçıların (Ahmet Hasan el-Bekr ve Saddam Hüseyin) rolleri üzerinde durulmaktadır. Rapora göre 2003 öncesi ve sonrası süreçte Irak'ta devam eden dinî bölünmeler, muhtemelen telafi edilemez sosyal parçalanmalara sebep olmaktadır. Zira işgal sürecinin karmaşasında kolektif öz savunma için örgütsel bir araç olan mezhepsel kimlikler bireysel ve grup davranışlarının şekillenmesinde etkili olmaktadır (s. 48). Bu çerçevede raporun bu kısmında özellikle Baas sonrası Irak’ta Şiilerin yükselişi, aynı dönemde Sünnî Irak kimliğin inişli çıkışlı hali ve bunun günümüz Irak'inda var olan mezhepçiliğe etkilerinden bahsedilmektedir. $\mathrm{Bu}$ bölümün son kısminda ise Irak'ta mevcut mezhepsel bölünmenin sonuçları ve bunun gelecekteki muhtemeletkileri değerlendirilmektedir (s. 53-70).

Raporun dördüncü bölümünde ise mevcut durumundan dolayı örneklem olarak seçilen bir diğer ülke olan Suriye'de mezhepçilik konusu ele alınmaktadır. Zira 2011'de başlayan ve siyasi çözüm açısından yok denecek kadar az umudun olduğu Suriye iç savaşının, öngörülebilir bir gelecekte devam etmesi muhtemeldir. Sünnî, Alevî 
(Nusayrî), diğer Şiî ve azınlık gruplar arasında var olan mezhepçilik, Suriye iç savaşının uzun süre devam etmesinde giderek artan bir role sahiptir. Bununla birlikte mezhepsel kimliği, Beşar Esed'e karş1 başlatılan olayların ana sebebi olarak göstermek konuyu oldukça basitleştirmek olacaktır (s. 71). Buradan hareketle raporun bu bölümünde kendi siyasî gündemleri doğrultusunda hükümetler ve grupların mezhepçiliği kullanmalarına rağmen, mezhepçiliğin Suriye'de devam eden iç savaşın altında yatan birkaç faktörden yalnızca biri olduğu savunulmaktadır. Zira coğrafya, siyasi zorunluluk, sınıf farklılıkları ve kabile bağll1ıklarından oluşan diğer faktörler, Suriye'de hem mezhepçilikten beslenmekte, hem de onu beslemektedir. Ayrıca Suriye'nin tarihi temelleri, çatışmada kendini açıkça kanıtlayan mezhepçiliği zorunlu kılmaz. Bununla birlikte Suriye'de devam eden bu iç savaşın nihayete ermemesi durumunda çatışmada tarafların mezhebi tercihlerinin rol oynama olasılığ artmaktadır (s. 72). Raporun bu kısminda bu önemli tespitler yapıldıktan sonra, Suriye'de etnik ve dinî grupların durumu genel olarak ele alınmaktadır. Ardından tarihi süreç içerisinde Suriye'de mezheplerin durumu, toplumsal konumları ve bağımsızlık öncesi ve sonrası kritik dönemlerde nasıl geliştikleri üzerinde durulmaktadır (s. 72-82). Daha sonra da 2011 iç savaşı esas alınarak Suriye'de mezhepçiliğin rolü ve bu rolün çatışma sürecine etki eden diğer faktörler arasında nasıl daha ön plana çıktığına değinilmektedir. Burada özellikle Beşar Esad hükümetinin varlığını devam ettirmek için Şî̀-Sünnî mezhepsel gerilimi artırdığı, Rejim ve muhalif unsurların mezhepsel saldırganlıklar yaptıkları ve Suriye'de mezhepçiliğin artmasında dış aktörlerin etkili olduğu ifade edilmeye çalış1maktadır. Özetle raporun bu kısmında 2011 sonrası Suriye'sinde var olan iç çatışmalarda iç ve dış aktörlerin kendi amaçları doğrultusunda mezhepçiliği nasıl kullandıkları üzerinde durulmaktadır.

Çalışmanın son bölümünde de politikacılar, araştırmacılar ve bölge üzerine planlama yapanlar için sonuç ve öneriler üzerinde durulmaktadır. Tarihsel bir yaklaşım benimseyen ve çeşitli birincil ve ikincil kaynakları kullanan bu rapora göre mezhepçilik, teolojik anlaşmazlıklar veya dinî husumetlerden daha ziyade sosyal, ekonomik, politik ve diğer faktörlerle şekillenen karmaşık bir 
olgudur. Ayrıca Sünnî ve Şiî ayrımın tarihinde ve Suriye ve Irak örnekleminde ele alındığ 1 üzere teolojik farklılıklar dışındaki faktörler, bölgede mezhepsel çatışmaların artmasında daha fazla etkili olmaktadır. Bu bağlamda raporda ulaşılan bulguları özetle şu şekilde vermek faydalı olacaktır: "Mezhep çatışması tamamen dinî olmaktan ziyade politik ve sosyaldir. Sünnî-Şiî çatışmasında itici güç çoğunlukla politiktir. Mezhepçilik bölgede var olan çatışmaları anlamada en önemli yol olmayabilir." Raporda ulaşılan bulgular bu şekilde verildikten sonra raporun sunulduğu kurum esas alınarak bazı öneriler sıralanmaktadır. Bunlar, "ABD'li politika yapıcılar ve savaş planlayıcılar, aşırı basitleştirmelerden kaçınmalıdır. Şiî ve Sünnîler arasında bir seçim yapmamalıdır. Bölgede yerel problemleri çözmek, mezhepçilikle mücadele etmekten daha önemlidir. Bölgede mezhepçiliği yerel veya devlet kurumlarında kurumsallaştıran politikalardan kaçınılmalıdır. Her ne kadar bu öneriler, raporun sunulduğu devlet ve silahlı kuvvetleri esas alınarak verilmiş olsa da bölge üzerinde araştırma yapanlar ve diğer devletler için oldukça önemlidir."

Genel olarak değerlendirildiğinde anlaş1lır bir dil ve üslupla yazılan bu rapor, ${ }^{4}$ bazı eksiklikleriyle birlikte birincil ve ikincil kaynaklara başvurulmak suretiyle hazırlanmıștır. Kanaatimizce raporun içeriği oluşturulurken biraz daha detay konulara yer verilerek bazı eksiklikler giderilmiş olsaydı ve özellikle Irak ve Suriye'nin anlatıldığı bölümlerde harita ve grafiklerden daha fazla yararlanılsaydı daha başarılı bir çalışma olurdu. Bunlarla birlikte rapor, Ortadoğu'da yaşanan hadiselerin arka planını oluşturan faktörler üzerine zihin yoran araştırmacıların, politika yapıcıların ve özellikle mezhepler tarihçilerinin istifade edeceği bir çalışma niteliğindedir.

4 Raporun pdf'sine https://www.rand.org/pubs/research_reports/RR1681.html adresinden ulaş1labilir (erişim: 30 Nisan 2019). 